Boletín de Arte $n^{\circ}$ 32-33, 2011-2012

Departamento de Historia del Arte

Universidad de Málaga 



\title{
varia
}

\section{Nuevos datos sobre la Inmaculada de la iglesia parroquial de San IIdefonso de Granada, una imagen de Pablo de Rojas}

\author{
José Antonio Peinado Guzmán \\ Universidad de Granada
}

La obra inmaculista del escultor Pablo de Rojas (1549-1611 aprox.) en Granada es bastante escasa. En comparación con otro tipo de iconografías que trabaja, como por ejemplo las de pasión, las de corte concepcionista no abundan, quizás porque el tema y la cuestión dogmática de la Inmaculada Concepción no estaban excesivamente maduros, como para desarrollar unos modelos escultóricos concretos. En ese sentido, las tallas inmaculistas clásicas que se le atribuyen al escultor alcalaíno son la Virgen de los Favores, originariamente ubicada en la iglesia de San Juan de los Reyes ${ }^{1}$, la Inmaculada del Monasterio de la Concepción y, finalmente, una imagen retocada con escaso acierto, de la capilla principal del Seminario Mayor diocesano. Asimismo, relacionadas con el círculo de Pablo de Rojas, se situarían las esculturas de las parroquiales del Salvador, la de San José del municipio de Pulianas, la de San Juan Bautista de la localidad de Mondújar o la de la clausura del convento de Carmelitas Calzadas de la Antigua Observancia.

Si bien todas estas atribuciones se realizan mediante la comparación estilística, difícilmente encontramos datos documentales que acrediten y avalen fehacientemente tales suposiciones. La escasez de información con respecto a la autoría de las obras artísticas es habitual en la época que tratamos, puesto que las variadas procedencias de las imágenes, los cambios de sede y titularidad dificultan tal empeño. Es por ello que, hallar alguna reseña de contrato o referencia que nos indique fecha o autor de la creación, adquiere una mayor relevancia.

Dicho esto, una de las primigenias imágenes concepcionistas que encontramos en Granada y que, indirectamente se relaciona con el trabajo de Rojas, se ubica en el conjunto del retablo mayor del Monasterio de San Jerónimo. Se trata de la Virgen Inmaculada con San Joaquín y Santa Ana, atribuido a Vázquez el joven y a Melchor de Turín, y fechado, aproximadamente, sobre $1573^{2}$.

1 La Virgen de los Favores ha estado guardada hasta febrero de 2012 en la Sacristía de Beneficiados de la Catedral de Granada. A partir de dicha fecha, se ha devuelto a su emplazamiento original.

2 Las referencias bibliográficas que tratan acerca de esta imagen son: GÓMEZ-MORENO, M. "La Inmaculada en la escultura española". Miscelánea Comillas (Comillas), XXIII (1955), p. 384, GALLEGO Y BURÍN, A Granada. Guía artística e histórica de la ciudad. Granada: Edit. Don Quijote, 1982, p. 293, GÓMEZ MORENO, M. Guía de Granada. Granada: Universidad de Granada, 1998, p. 370, MARTíNEZ JUSTICIA, M. J. La vida de la Virgen en la escultura granadina. Madrid: Fundación Universitaria Española, 1988, pp. 31s. y 48s., MARTÍN ROSALES, F. y ROSALES FERNÁNDEZ, F. Pablo de Rojas. Escultor de imaginería. Maestro de Juan Martínez Montañés. Alcalá la Real: Gráficas La Paz, 2000, pp. 185s., LEÓN COLOMA, M. A. "La Inmaculada Concepción en la escultura granadina". En: A María no tocó el pecado primero. "La Inmaculada en Granada". Córdoba: Publicaciones Obra Social y Cultural Cajasur, 2005, pp. 251s., AA. VV. Guía artística de Granada y 


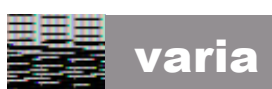

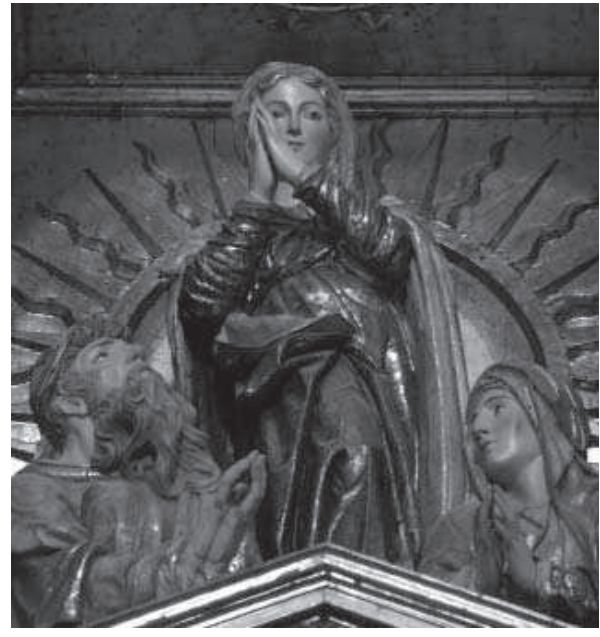

1. Virgen Inmaculada con San Joaquín y Santa Ana del retablo mayor del Monasterio de San Jerónimo. Juan B. Vázquez, el mozo y Melchor de Turin, c. 1573.
En torno a 1580, encontramos ya trabajando a Pablo de Rojas en el retablo de dicha comunidad jerónima. De este modo, el escultor entraría en contacto con el magisterio del citado Juan Bautista Vázquez. De este modo, esa influencia se ve claramente en la imagen que nos atañe, la Inmaculada de la parroquial de San Ildefonso, que como veremos, sale de las gubias del maestro alcalaíno.

La talla de la Purísima que se aprecia, presenta considerables semejanzas con la mencionada escultura del templo de San Ildefonso. Ubicada en la hornacina central del segundo cuerpo del retablo mayor, la figura de María se nos presenta erguida, ante los bustos de los ancianos padres. La observamos ataviada con túnica

dorada, sobre la que se aprecia decoración en grisalla, de corte clásico. La cabeza aparece cubierta por una toca blanca, que deja entrever su cabello rubio. El manto, de tonalidad azul y reverso blanco, se dispone sobre los hombros, con un tratamiento de los paños muy vertical. A la par, se percibe que dicha prenda se ciñe sobre su pierna izquierda, con fino plegado, y en la que se vislumbra en su parte inferior, una delicada cenefa estofada con motivos clasicistas.

En el rostro, de carnación rosada, se observan finas cejas arqueadas, con ojos rasgados, y boca pequeña. Los brazos, alzados a la altura del pecho, se giran suavemente hacia la derecha, dejando ver el semblante con claridad. Asimismo, une las palmas de sus manos. Esta disposición contribuye a la composición sinuosa del conjunto de la imagen, característica muy manierista con la que se imprime dinamismo a esta imagen de estática actitud.

La imagen se encuentra enmarcada mediante una ráfaga que aparece labrada en el fondo de la hornacina. En la parte superior de la misma, igualmente, apreciamos las doce estrellas circundando un tondo. En el mismo, aparecen una serie de rayos que debieron servir de destellos de una posible representación del Espíritu Santo.

A los pies de la Virgen se sitúan San Joaquín y Santa Ana. Representados en bustos, el padre es colocado en la parte inferior izquierda, mientras que su esposa la contemplamos en similar disposición, a la derecha. El anciano, de amplias barbas

su provincia. (vol. I) Sevilla: Fundación José Manuel Lara, 2006, p. 158. 
grisáceas resueltas en mechones, viste túnica verde y manto rojo. Cubre su cabeza con pequeño gorro. Santa Ana aparece ataviada con túnica azul y manto rojo. Asimismo, cubre su cabeza con toca blanca. Tanto las vestimentas de San Joaquín como las de su esposa, se presentan estofadas. Ambos unen sus manos en actitud reverente, a la par que miran la imagen de María.

El parecido entre esta imagen y la de la parroquia de San Ildefonso, ha hecho pensar que ambas compartían una misma autoría, esto es, de Vázquez el joven o el mozo ${ }^{3}$. Así pues, contemplamos la imagen mariana según la disposición habitual, de pie, sobre la luna en creciente con las puntas hacia arriba, a la par que se vislumbra como dosel de sus pies, cabezas aladas de ángeles rodeadas de nubes. Adelanta la pierna izquierda, a la par que deja en reposo la opuesta. La bestia, en la parte inferior, se representa como una mezcla de serpiente y dragón. La Virgen une sus manos a la altura del pecho, ligeramente separadas del mismo y levemente orientadas a la derecha. Sus palmas unidas se disponen de modo vertical. Como detalle, se ha de reseñar que la finalización de las manos, guarda una gran semejanza con la que observamos en el San Joaquín del citado Monasterio de San Jerónimo. Esto nos muestra la comentada influencia que Vázquez, el

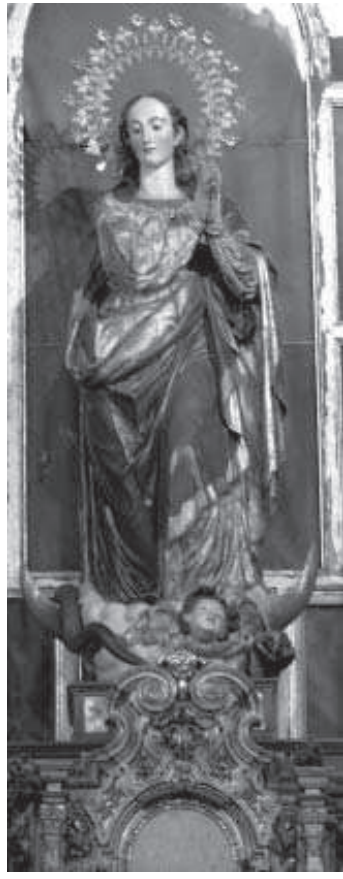

2. Inmaculada de la iglesia parroquial de San Ildefonso. Pablo de Rojas, 1585. mozo ejercerá sobre Rojas. Si bien el torso sigue la misma dirección que los brazos, la cabeza se gira al lado opuesto, generando cierta movilidad en la imagen. Eso, unido a la pose de las piernas, nos ofrece un claro contraposto. El rostro refleja la belleza clásica, con las cejas arqueadas, ojos grandes almendrados, nariz afilada y pequeña boca. Su cabello, ondulado, oscuro y largo se dispone sobre hombros y pecho. Nos permite ver su cara con nitidez, a la par que nos muestra sus orejas enmarcadas entre el mechón de pelo, detalle muy característico en la obra de Rojas. Como exorno, decora su cabeza con la corona de doce estrellas.

La Virgen se atavía con túnica dorada, según la técnica del estofado, que va desarrollando una decoración vegetal punteada en la prenda. Similares motivos

3 Referencias sobre esta imagen las encontramos en: GÓMEZ-MORENO, M. "La Inmaculada en la escultura española”. Miscelánea Comillas.... p. 384, GALLEGO Y BURÍN, A. Granada. Guía artística..., p. 314, MARTÍNEZ JUSTICIA, M. J. La vida de la Virgen..., pp. 50s., LEÓN COLOMA, M. A. "La Inmaculada Concepción en la escultura granadina". En: A María no tocó el pecado primero..., p. 252, SÁNCHEZ FUNES, J. C. y CURIEL SANZ, A. J. La iglesia de San IIdefonso de Granada. Granada: Velocitynet, 2004, p. 17, AA. VV. Guía artística de Granada y su provincia (vol. I)..., p. 173, LÓPEZ-GUADALUPE MUÑOZ, J. J. "Pablo de Rojas, encrucijada de las escuelas andaluzas". En: La escultura del primer naturalismo en Andalucía e Hispanoamérica (15801625). Granada: Editorial Arco/Libros, 2010, p. 171. 
policromados, en flores con tonos rojos, verdes y azules, se distribuyen por la misma. El plegado de la vestimenta se acentúa en los brazos y en la parte inferior. Siguiendo la dirección del ropaje, se contemplan suaves y abundantes, trazando líneas marcadamente diagonales. Asimismo, se cubre con manto azul terciado que, de izquierda a derecha, cae sobre el hombro izquierdo de la imagen, sin sujetarse en los brazos. Por el borde del paño, se percibe una cenefa en oro, con similar decoración punzada. La caída de la prenda por el flanco diestro, nos permite contemplar un gracioso pliegue en corbata. Igualmente, y debido al adelantamiento de la pierna izquierda de la Virgen, sobre la que queda en reposo se desarrollan una serie de plisados marcados, dibujando el típico triángulo invertido, que elabora Rojas habitualmente bajo la cintura de sus tallas.

Descrita la imagen que consideramos su antecedente, la de San Jerónimo, así como la que nos atañe, pasamos ahora a analizar los datos que centran nuestro interés. Para ello nos acercaremos a la figura de Antonio de Terradas, quien fuera contador del rey de los bienes confiscados a los moriscos. En su testamento, fechado el 28 de noviembre de 1588, en primer lugar, nos informa de su pertenencia a la cofradía de la Limpia Concepción de Nuestra Señora, ubicada en San Francisco Casa Grande. Pero quizás este dato sea el menos relevante. A través de ese documento, descubrimos cómo posee una capilla bajo la advocación de la Limpia Concepción, situada en el antiguo convento de la Merced. Y es que como demuestra su última voluntad, deseaba que su "cuerpo sea sepulttado en el monesterio de nuestra señora de las Merzedes extramuros de esta çiudad de Granada en vna capilla que tengo en dicho monestterio de la bogazion de la limpia consibision de nuestra señora la Sanctissima birxen Maria". Además de esto, nos ofrece una detallada información de la mencionada capilla de sumo interés. Entre los detalles más importantes que se muestran, se nos relata que el retablo de la misma fue encargado a Pablo de Rojas, por el precio de doscientos sesenta ducados. La pintura del mismo y las de sus imágenes, entre las que estaba una de la Concepción, fueron realizadas por el maestro Baltanás. El coste de ello, en un principio, se tasó en ciento sesenta ducados. Pero las discrepancias con el pintor fueron tales, puesto que éste se veía engañado, que Terradas tuvo que pagarle finalmente doscientos veinte ducados por el trabajo. Colaborando en aquel retablo estaba como dorador Ginés López y como platero, Luis de Beas. $Y$ todo esto a fecha de 23 de noviembre de 1585. Reproducimos a continuación el texto del testamento, donde se especifican los detalles del contrato con sus respectivos pagos:

"Yttem mando que por quantto a el presente que 22 r./ hago estte mi testamento en la dicha mi capilla que ansi tengo en el dicho monesterio no tiene puesto retablo en el altar della como quede obligado a el dicho monesterio de lo hazer a el tiempo que me la bendieron como consta de las escripturas que dello se ottorgaron por ante françisco perez escriuano publico que fue desta çiudad que a el presente estan en mi poder el qual dicho rettablo di a hazer e hizo Pablo 


\section{践}

de Rojas escultor vezino de esta çiudad de Granada que bibe en la calle de Eluira y pagadole doszienttos sesenta ducados que con el conçerte de le dar por que lo diera acauado de todo punto labrada la madera 22 vto. y mas hechura y por todo y hechura y por lo demas me obligue de le dar y pagar los dichos dozientos sesenta ducados y que lo auia de hazer como lo hizo conforme una traça que para ello se hizo de que se hace minsion en la dicha escriptura de conçierto entre mi y el fecha que paso ante Martin de Auila escribano Real de su magestad que reside en esta çiudad a la plaça nueua que orixinalmente esta en mi poder por manera que el suso dicho hizo el dicho retablo e yo le tengo pagados los dichos dozientos y sesentta ducados ${ }^{23}$ r./ que por razon de el obo de hauer y demas de los dichos maravedis pagadole ansimismo otros en zierta cantidad en que entre el y mi nos conbenimos y conzertamos por razon de ziertas demasias que auia hecho en dicho retablo de que de lo vno y de lo otro constará de los dichos recados y por sus cartas de pago que de ello estan ansimismo en mi poder ponerse aqui por adbertençia y de que esta y queda todauia obligado el dicho Pablo de Roxas acabado que se aia de dorar y pintar el dicho retablo que esto sea de hazer a mi costta de asentar a costa suia ${ }^{23}$ vto./ del dicho Pablo de Roxas el dicho retablo a la dicha capilla sin que por razon de ello sea obligado yo ni mis herederos a le dar cosa ninguna como pareçiere de la dicha escriptura y si a el tiempo de mi fallezimiento el dicho retablo no estubiere puesto en la dicha capilla mando que si estubiere acabado de dorar y pintar que el suso dicho lo ponga y sino quando lo estubiere, y sino quesiere que se haga asentar a su costa por estar obligado a ello como dicho es.

Yttem digo y declaro que io estava combe- 24 r./nido y conzertado con maestro Baltanas pintor vezino de esta çiudad que a el presente biue en la calle de Eluira que el susodicho me auia de dorar todo el dicho retablo y dar los colores nezesarios y estofar a punta de pinzel las ymaxenes del dicho retablo y darlo de todo punto acauado y puesto en perfecçion todo ello a su costa y en la forma y manera que se contiene en la escriptura de contrato que entre el y mi hizimos que paso ante Juan Ayllon escribano de su magestad que reside en el oficio de Rodrigo Dauila escribano publico de esta 24 vto./ çiudad por la qual yo me obligue de la dar y pagar por todo ello ziento sesenta ducados y aunque doro y labro la ymaxen de Nuestra Señora de la limpia conçepçion del dicho retablo de todo punto y comenzo a las labrar otras el suso dicho dijo no podia acauarlas ni dorar el dicho retablo labrarlo de todo punto como estaba obligado por perderse en el y auer sido en el engañado en mucha cantidad de maravedies encargamdome la conçiencia y que para que no se perdiese en el que se viese por maestros que de ello entendieren y bisto e que yo ${ }^{25}$. / le pagase lo que en ello auia labrado y diese por libre de la dicha escriptura o le gratificase el mas valor que mereçia la dicha obra y la acrecentada en ella y auiendose puesto maestros asi por mi parte como por la suia del dicho arte se resumieron y ambos el dicho maestro Baltanas e yo el dicho contador quedamos resumidos y combenidos $y$ 
conzertados en la dicha manera siguiente.

Que yo el dicho contador Antonio de Terradas le diese sesenta ducados mas por razon de todas las dichas sus ${ }^{25}$ vto./ pretensiones y por lo que mas se auia acreçentado en el dicho retablo por manera que como me auia obligado a pagarle por ello zientto sesenta ducados fuesen otros sesenta ducados mas que en todos harian y haçen duszientos y veinte ducados y por tenerles ya pagados por lo que estaba obligado por el primer contrato y en quenta de los ziento sesenta ducados en el contenidos quarenta ducados por sigundo contrato que despues sobre ello hizimos y por escriptura ${ }^{26}$ r./ que de ello otorgamos en esta çiudad de Granada a veintitres de Noviembre de mill y quinienttos y ochenta y çinco por ante Juan de Aguilera escribano de su magestad veçino de esta dicha çiudad a la puerta de Eluira me obligue a pagar al dicho maestro Baltanas pintor y a Gines Lopez dorador que en este contrato entro por su conpañero los ziento y ochentta ducados restantes cumplimiento a los dichos dozientos ducados en esta manera los çinquenta ducados de ellos para en fin del mes de 26 vto./ diziembre del dicho año pasado de mill e quinientos ochenta y çinco y los otros çinquenta ducados para en fin del mes de junio que paso de este presente año de mill y quinientos y ochenta y seis años y los ochentta ducados restantes cumplimiento a los dichos dozienttos y veintte ducados para en fin del mes de diziembre siguiente del dicho año estando acabado de labrar de todo punto el dicho retablo y puesto y asentado en la dicha capilla qu el asiento del como esta dicho a de ser acosta del dicho Pablo de Rojas y el dicho maestro 27 r./ Baltanas pintor y Gines Lopez dorador ansimismo vezino de esta çiudad frontero de los hospitales prinçipales y Luis de Beas plattero ansimismo vezino de esta çiudad a la parroquia de la yglesia maior con su fiador todos tres de mancomun se obligaron a dar acauado de todo punto el dicho retablo en la manera segun se contiene en la dicha primera escriptura y capitulo que trata de ella que estan escritos en la espalda de la traza que del dicho retrablo se hizo que esta en mi poder y a lo contenido al ultimo contrato a todo lo qual me refiero ${ }^{27}$ vto./ y porque hasta agora en quenta de los dichos ziento y ochenta ducados que ansi se les quede deuiendo no les e pagado mas que zinquenta ducados de la primer paga que ansi les auia de hazer en el dicho mes de diziembre del dicho año pasado de quinientos y ochenta y çinco y les soy e quedo deudor hasta oy dia de la fecha de este mi testamento de los ziento y treinta ducados restantes mando que se les paguen luego otros zinquenta ducados por ser cumplido el plazo de la paga que les auia de hazer de ellos si no lo estubiera al tiempo ${ }^{28} \mathrm{r} . / \mathrm{de}$ mi fallezimiento, y que si no estubiera acabado el dicho retablo que se les de priesa o apremien a ello y a que se ponga y asiente en el altar de la dicha capilla y que quedandolo este se les acauen de pagar los ochenta ducados restantes y sea de adbertir que si algunas ymaxenes o otras qualquier piezas del dicho retablo se quebraren o maltrataren que las an de aderezar todas a su costa por auerlas rezeuido enteras y bien trauidas del dicho Pablo de Roxas escultor 
y estar obligados a ello sin que io lo estte de les pagar por ello cossa alguna 28 vto./ y cumplido que los suso dichos aian lo contenido en los dichos contratos $y$ acauado que este como dicho es de todo punto y en toda perfeçion el dicho rettablo y asentado que se aia en el altar de la dicha capilla si no lo estubiese a el tiempo de mi fallezimiento y pagados de los dichos maravedis que luego se de orden como se ponga y de mis bienes hazerles pagado de lo que pareziere quedarles deuiendo que constar por la cuenta que con ellos tengo que esta con otras en vn libro que esta en mi poder yntitulado libro que es donde tengo las quentas con $29 \mathrm{r} . /$ particulares ansi de lo que me deuen como de lo que io debo a otros por la qual constara de lo suso dicho a que me refiero y a otros recaudos que esttaran en mi poder y sus cartas de pago".

La imagen de la Concepción que hiciera Pablo de Rojas, sería trasladada a la parroquia de San Ildefonso desde el convento de la Merced, tras la desamortización definitiva del mismo en $1835^{5}$. Tal y como consta en el inventario de la parroquia de San Ildefonso de 1842, en uno de sus apartados, se citan las obras de arte que procedían del suprimido claustro mercedario. Entre ellas se encontraba una imagen de la Purísima Concepción ${ }^{6}$. Tanto por los documentos, como por el parecido estilístico a la obra de Rojas, podemos concluir que esa escultura es la que hoy se venera en la capilla lateral derecha, al pie del altar de la dicha parroquia de San Ildefonso.

4 Archivo del Monasterio de Santa Isabel la Real, Leg. 9, n² 27, 52 hojas. Traslado de 5 de octubre de 1712 en Granada. Incluido en "Pleito de la Hermandad de Nuestra Señora de la Concepción que se venera en el Convento de San Francisco Casa Grande contra sor Mariana Maldonado, religiosa en el Monasterio de Santa Isabel la Real, sobre la propiedad del mesón llamado de la Cruz y otros bienes que quedaron por muerte de Antonio de Terradas, esposo de su tía abuela...", fols. 22 r. -29 vto.

5 Henríquez de Jorquera cita la existencia de la imagen y del retablo en el convento de la Merced, calificándola como "una imajen de la Concepción Santisima con un vizarro retablo". HENRÍQUEZ DE JORQUERA, F. Anales de Granada. Edit. Antonio MARÍN OCETE. Granada: Universidad de Granada. Excmo. Ayuntamiento de Granada, 1987, p. 238.

6 Archivo Histórico Diocesano de Granada, Inventarios, Leg. 10, pza. 23, s. f., Archivo de la Parroquia de San Ildefonso, Ynventario general de los objetos contenidos en la Yglesia Parroquial de San Yldefonso siendo Cura Don Mariano Maeso. Año 1895, fol. 3. 
